|| ISSN(online): 2589-8698 || ISSN(print): 2589-868X || International Journal of Medical and Biomedical Studies

Available Online at www.ijmbs.info

Volume 3, Issue 2; February: 2019; Page No. 120-123

PubMed (National Library of Medicine ID: 101738825)

Index Copernicus Value 2017: 40.03

\title{
TO ANALYZE ASSOCIATION OF LEVEL 3 LYMPH NODE METASTASIS WITH VARIOUS CONTRIBUTING FACTORS
}

Dr. Abhinav Pandey ${ }^{1}$ (Resident), Dr. Jubin Sonane ${ }^{2}$ (Resident) \& Dr. Rajgovind Sharma ${ }^{3}$ (Prof. \& Head)

Dept. of Surgery, SMS Medical College and Hospital, Jaipur ${ }^{1,2 \& 3}$

Article Info: Received 2 February 2019; Accepted 26 February. 2019

Cite this article as: Pandey, Dr. A., Sonane, Dr. J., \& Sharma, Dr. R. (2019). TO ANALYZE ASSOCIATION OF LEVEL 3

LYMPH NODE METASTASIS WITH VARIOUS CONTRIBUTING FACTORS. International Journal of Medical and Biomedical Studies, 3(2).

DOI: https://doi.org/10.32553/ijmbs.v3i2.119

Address for Correspondence: Dr. Abhinav Pandey, Dept. of Surgery, SMS Medical College and Hospital, Jaipur Conflict of interest: No conflict of interest.

\section{Abstract}

This study is to Analyze Association of Level 3 Lymph Node Metastasis with various contributing factors was conducted at SMS, Medical College \& Hospital, Jaipur.

Lump was most common symptom of presentation with pain and nipple discharge distant second and third. Nipple areola complex and skin involvement was less.

Mean duration of symptom before diagnosis was 3.61 months and in those with level III positivity it was 4 months. It was higher than western studies but similar to other studies in India and developing countries, reflecting delay in seeking medical opinion.

Keywords: Level 3, Lymph Node \& Metastasis.

\section{Introduction:}

Nearly all breast cancer cases are clinically detected in India ${ }^{1}$, with the majority presenting with locally advanced disease. ${ }^{2}$ One-third of breast cancer patients have skin/chest wall involvement at the time of diagnosis and the stage at diagnosis is often worse in younger patients. $^{3}$

Radical mastectomy was first defined by Halsted which included removal of breast tissue, with pectoralis major and pectoralis minor and en bloc resection of axillary contents including all level of lymph nodes. It was later modified by Patey in which Pectoralis major was preserved and pectoralis minor was divided at its tendon for level III lymph node clearance.

Today the standard surgical treatment for breast cancer is modified radical mastectomy which includes level I + II lymph node dissection/ Breast conservation surgery with axillary dissection/ Mastectomy with sentinel lymph node biopsy followed by chemotherapy and radiotherapy if required. ${ }^{4}$

\section{Material \& Method}

Study Population: On basis of Inclusion and exclusion criteria, Carcinoma Breast patients reporting to Oncosurgery Department posted for MRM, Completion MRM, Breast conservation surgery for January 2013 to August 2014; 18 months.

\section{Sample Size:}

Expecting $31.1 \%$ involvement of level 3 lymph node in breast carcinoma (as per seed article), the sample size required to find out this proportion at $95 \%$ confidence and $80 \%$ power and $15 \%$ allowable 146 breast carcinoma cases were included in this study. 
Inclusion Criteria:

1. Histopathologically proven invasive breast carcinoma undergoing Modified Radical Mastectomy (MRM), Breast Conservation Surgery (BCS).

2. Histopathologically proven breast carcinoma who had undergone lumpectomy and now posted for Completion MRM.

\section{Exclusion Criteria:}

1. Patients who have received neoadjuvant chemotherapy.

2. Patients with only Carcinoma in situ.

3. Metastatic Breast Carcinoma.

\section{METHODOLOGY:}

After taking informed consent patients were assessed on clinical history, clinical examination and after histopathological confirmation proven breast carcinoma patients underwent Modified Radical Mastectomy (MRM) and Complete Axillary Lymph Node Dissection / Breast Conservation Surgery (BCS) and Complete Axillary Lymph Node Dissection/ Completion Modified Radical Mastectomy And Complete Axillary Lymph Node Dissection in the Surgical Oncology Division, Department of General Surgery, SMS Hospital during period of study.

All axillary dissections were performed with the retraction of pectoralis minor muscle and removal of all lymph node bearing fibroadipose tissue inferior to the axillary vein from Halsted's ligament medially, to the latissimus dorsi laterally and inferiorly to the junction of the thoracodorsal vessels with the latissimus dorsi and long thoracic nerve with the serratus anterior muscle.

Results

Table 1: Level III (Apical) Lymph Node

\begin{tabular}{|l|l|l|l|}
\hline & $\begin{array}{l}\text { Level III Detected in } \\
\text { Final Histopathology }\end{array}$ & $\begin{array}{l}\text { No Level III } \\
\text { Detected in Final } \\
\text { Histopathology }\end{array}$ & Total \\
\hline $\begin{array}{l}>/=2 \text { Lymph Node Positive in Level } \\
\text { I+II }\end{array}$ & $37(25.34 \%)$ & $17(11.64 \%)$ & $54(36.98 \%)$ \\
\hline$<2$ Lymph Node Positive in Level I+II & $81(55.47 \%)$ & $11(7.53 \%)$ & $92(63.01 \%)$ \\
\hline Total & $118(80.82 \%)$ & $28(19.17 \%)$ & $146(100 \%)$ \\
\hline
\end{tabular}

Eight patients $8 / 146$ (5.47\%) had metastasis in Level III lymph node on final histopathology. Out of these 8 patients, 7 had gross involvement in Level I+II lymph node with either 2 or more than 2 lymph node positive on histopathology.

Out of 146 patients no level III lymph node was detected in 28(19.17\%) of patients. However for intention to treat analysis all patients were included in final statistical analysis.

Table 2:

\begin{tabular}{|l|l|l|l|}
\hline & 0-2 L.N. Positive in Level I+II & >2 L.N. Positive in Level I+II & Total \\
\hline Level III Negative & $111(80.43 \%)$ & $27(19.56 \%)$ & $138(100 \%)$ \\
\hline Level III Positive & $2(25 \%)$ & $6(75 \%)$ & $8(100 \%)$ \\
\hline Total & $113(77.39 \%)$ & $33(22.61 \%)$ & $146(100 \%)$ \\
\hline
\end{tabular}

$6 / 8$ (75\%) of cases who had Level III metastases also had more than 2 metastatic LN in Level I+II. This correlation was also found to be statistically significant $(p=0.001)$ on Fisher test and chi square test. 
Table 3:

\begin{tabular}{|l|l|l|l|}
\hline & Level III Positive & Level III Negative & Total \\
\hline pT2 & $5(3.84 \%)$ & $125(96.16 \%)$ & $130(100 \%)$ \\
\hline pT3 & $3(42.85 \%)$ & $4(57.15 \%)$ & $7(100 \%)$ \\
\hline Total & 8 & 129 & 137 \\
\hline
\end{tabular}

Patients diagnosed to have level III lymph node involvement were all pT2 and pT3 stage. Out of 7 pT3 stage patient $3(42.85 \%)$ had level III lymph node involvement which was found to be statistically significant ( $p$ value $<0.004$ ) on Fisher's test.

\section{Discussion:}

\section{Lymph Node Dissection and Level III Lymph Node Involvement}

In our study $71 / 146(48.63 \%)$ patient had involvement of axillary lymph nodes Epstein RJ et al found $35 \%$ to $50 \%$ of patients with clinically detected invasive cancer prove to be node positive following axillary lymph node dissection (ALND). ${ }^{5}$

Sabahattin Aslan et al in their study of 87 patients observed that $71.2 \%$ had axillary lymph node metastases. ${ }^{6}$

Ashraf S. Zaghloul, et al. in their study of 50 patients observed $82 \%$ axillary lymph node metastasis. $^{7}$

Murlee $\mathrm{M}$ et al in their study of 200 patient onserved 92/200(46\%) had axillary lymph node metastasis. $^{8}$

Comparatively less nodal positivity noted in our study was due to fact that majority of our patients were early stage breast cancers clinical T1 and T2 95/146(65.06\%) and in final histopathology 136/146(93.14\%) patients were pT1 and pT2.

\section{Conclusion}

Lump was most common symptom of presentation with pain and nipple discharge distant second and third. Nipple areola complex and skin involvement was less.
Mean duration of symptom before diagnosis was 3.61 months and in those with level III positivity it was 4 months. It was higher than western studies but similar to other studies in India and developing countries, reflecting delay in seeking medical opinion.

\section{References}

1. Leong SP, Shen ZZ, Liu TJ, et al. Is breast cancer the same disease in Asian and Western countries? World J Surg; 34:230824.

2. Chopra R. The Indian scene. J ClinOncol 2001; 19:106S-11S.

3. Mathew A, Pandey M, Rajan B. Do younger women with non-metastatic and noninflammatory breast carcinoma have poor prognosis? World J SurgOncol 2004; 2:2.

4. National Comprehensive Cancer Network. Breast Cancer (Version 1.2015). http://www.nccn.org/professionals/physicia n_gls/pdf/breast.pdf.AccessedFebruary 6, 2015.

5. Epstein RJ. Routine or delayed axillary dissection for primary breast cancer.Eur J Cancer 1995;31:1570-3

6. Sabahattin Aslan, BahadirÇetin, MelihAkinci, Akin Önder, Ahmet Seki, Hüseyinincir, Abdullah Çetin: Level III lymph node involvement in breast carcinoma. Turkish Journal of Cancer 109 Volume 37, No. 3, 2007

7. Ashraf S. Zaghloul, Wael A. Ghoneim, Tarek Abd El-Moneim, Nabhan T. Kaddah, Nabil El 
Dr. Abhinav Pandey et al, International Journal of Medical and Biomedical Studies (IJMBS)

Bolkainy, Medhat M. Khafagy: Patterns of Axillary Lymph Node Metastasis from Breast Cancer in Egyptian Patients. Journal of the Egyptian Nat. Cancer Inst., Vol. 13, No. 1, March: 1-8, 2001
8. Murlee $\mathrm{M}$, Lekha $\mathrm{N}$, Ahmed IM: Involvement of level III axillary lymph node in breast cancer and factors predicting it. Indian J Cancer. Vol. 50, No.1,Nov: S12, 2013 